\title{
Cinética de fermentação in vitro de silagens da parte aérea de mandioca
}

\author{
Kinetics of "in vitro" fermentation of the silage shoots of cassava
}

\author{
MARQUES, Kléria Maria Souza ${ }^{1}$; ROCHA JÚNIOR, Vicente Ribeiro ${ }^{1 *}$; REIS, Sidnei \\ Tavares dos ${ }^{1}$; SOUZA, Vanice Mendes de ${ }^{1}$; PIRES, Daniel Ananias de Assis ${ }^{1}$; \\ PALMA, Malber Natham Nobre de ${ }^{1}$; SILVA, Geanderson Walder Vieira da Silva ${ }^{1}$; \\ ANTUNES, Ana Paula da Silva ${ }^{1}$
}

\begin{abstract}
${ }^{1}$ Universidade estadual de Montes Claros, Centro de Ciências Exatas e Tecnológicas, Departamento de Ciências Agrárias, Janaúba, Minas Gerais, Brasil.

*Endereço para correspondência: vicente.rocha@ unimontes.br
\end{abstract}

\section{RESUMO}

Objetivou-se com esta pesquisa avaliar a cinética de fermentação ruminal das silagens de diferentes frações da parte aérea de variedades de mandioca, pela técnica semiautomática de produção de gases. O experimento foi conduzido em um delineamento inteiramente casualizado, com quatro repetições, arranjado em um esquema fatorial $4 \times 3$, sendo quatro variedades de mandioca (Amarelinha, Sabará, Olho roxo e Periquita) e três frações da parte aérea (terço superior, sobra de plantio e planta inteira). $\mathrm{O}$ material foi ensilado em silos experimentais de PVC, sendo abertos após 56 dias de fermentação. Amostras das silagens foram coletadas e submetidas à pré-secagem, moídas e em seguida procedeu-se ensaio de produção de gases in vitro. As leituras de pressão dos gases produzidos durante as fermentações foram realizadas às $0 ; 4 ; 6 ; 8 ; 10 ; 12 ; 15 ; 18 ; 21 ; 24 ; 30$; 36; 48; 72 e 96 horas após o início das incubações. As leituras de pressão dos gases foram realizadas por intermédio de transdutor de pressão e, posteriormente ajustadas para o volume de gases. O maior desaparecimento ruminal da MS ocorreu nos tempos entre zero e 24 horas. As maiores produções de gases por hora foram obtidas aproximadamente às 48 horas de fermentação para a variedade Olho Roxo na fração planta inteira. As silagens das diferentes variedades e frações da parte aérea de mandioca apresentaram o mesmo potencial de produção de gases. Entretanto, as silagens da variedade Amarelinha nas frações da parte aérea terço superior e sobras de plantio apresentaram melhores degradabilidades efetiva e potencial.

Palavras-chave: degradabilidade, digestibilidade, forragem, ruminantes.

\section{SUMMARY}

The objective of this work to determine Kinetics of ruminal fermentation of silages of different fractions of the aerial parts of cassava varieties by technical semiautomatic gas production. The experiment was conducted in a completely randomized design with four replications, arranged in a $4 \times 3$ factorial design, four varieties of cassava (Amarelinha, Sabará, Olho Roxo e Periquita) and three fraction of shoots (upper, left over planting and whole plant). The material was ensiled in mini-silos of PVC, being opened after 56 days of fermentation. Silage samples were collected and submitted to pre-dried, ground and then proceeded to test gas production in vitro. The pressure readings of the gases produced during fermentations were performed at $2 ; 4 ; 6 ; 8 ; 10 ; 12$; $15 ; 18 ; 21 ; 24 ; 30 ; 36 ; 48 ; 72$ and 96 hours after the start of incubations. Pressure readings were made of gases through pressure transducer and subsequently adjusted to the volume of gases. The major ruminal DM disappearance occurred in times between zero and 24 hours. The highest yields of gas per hour were obtained at approximately 48 hours of fermentation for variety in Shiner fraction entire plant. The silages of different varieties and fractions of cassava shoots have the same potential for gas production. However, silage variety of Hopscotch fractions in the upper third of shoot and leftover planting have better effective degradability and potential.

Keywords: degradability, digestibility, roughage, ruminant. 


\section{INTRODUÇÃOO}

Um dos enfoques da pecuária atual é a busca por fontes de alimentos menos onerosos para a formulação de dietas para os animais. O conhecimento da composição química e o valor nutricional desses alimentos são imprescindíveis, para saber a sua real aplicabilidade nos sistemas de produção. A cultura da mandioca (Manihot esculenta Crantz), tradicionalmente cultivada em países de clima tropical, destaca-se em decorrência da facilidade de cultivo, adaptabilidade a diversos tipos de solos, resistência a períodos de estiagem e expressiva produção, além da possibilidade de utilização da sua parte aérea. Entretanto, a utilização da parte aérea da mandioca na alimentação animal ainda tem sido pouco frequente, o que pode ser atribuído, especialmente, por desconhecimento do seu valor nutricional e potencial no tocante à produção animal (FERREIRA et al., 2007; MODESTO, et al., 2004; MOTA et al., 2011; NUNES IRMÃO et al., 2008; SOUZA et al., 2011; SOUZA et al., 2012).

A potencialidade dos alimentos a serem utilizados na alimentação de ruminantes deve ser comprovada por meio da determinação do seu valor nutritivo, que mantém relação direta com sua digestibilidade. Tais determinações podem ser obtidas por métodos in vivo, in situ ou in vitro (FIGUEIREDO et al., 2006; MAURICIO et al., 1999).

Os sistemas in vitro, que incluem a técnica de produção de gases, são cada vez mais empregados na análise dos nutrientes utilizados pelos ruminantes, em virtude do baixo custo, rápida execução, confiabilidade, possibilidade de avaliação de grande quantidade de alimentos por ensaio e por utilizar poucos animais fistulados (BARCELOS et al., 2001; GIRALDO et al., 2006). Assim, objetivou-se avaliar a cinética de fermentação ruminal por meio da técnica in vitro semiautomática de produção de gases das silagens de diferentes frações da parte aérea de quatro variedades de mandioca.

\section{MATERIAL E MÉTODOS}

O experimento foi conduzido na Fazenda Experimental da Universidade Estadual de Montes Claros UNIMONTES, localizada no município de Janaúba, Norte de Minas Gerais e no Laboratório de Análises de Alimentos do Departamento de Ciências Agrárias da UNIMONTES, campus de Janaúba. Utilizou-se o delineamento em blocos casualizados, com esquema fatorial $4 \times 3$, quatro variedades de mandioca (Manihot esculenta Crantz "Amarelinha", Manihot esculenta Crantz "Olho Roxo", Manihot esculenta Crantz "Periquita" e Manihot esculenta Crantz "Sabará") e três frações da parte aérea (planta inteira, terço superior e sobras de plantio) com quatro repetições cada.

$\mathrm{O}$ plantio foi efetuado usando quatro canteiros (parcelas) com quatro linhas por variedade, seguindo as recomendações técnicas para a cultura e as metodologias tradicionais de cultivo empregadas pelos produtores locais, procedendo-se a coleta do material aos oito meses de idade, no respectivo estádio fenológico indicado para a colheita da raiz.

As plantas de cada canteiro foram separadas em três partes iguais, e isoladamente utilizadas para a produção de forragem com as seguintes frações da parte aérea: forragem composta pela parte aérea total, forragem composta apenas pelo terço superior da parte aérea e forragem composta pela parte aérea restante após a produção de 
manivas necessárias para novo plantio na mesma área. Essas forragens foram individualmente picadas em tamanho médio de partícula de $2 \mathrm{~cm}$ e manualmente homogeneizadas

A produção da silagem foi realizada em silos confeccionados com tubos de PVC de $10 \mathrm{~cm}$ de diâmetro por $50 \mathrm{~cm}$ de comprimento, tendo $10 \mathrm{~cm}$ preenchido com areia para determinação da produção de efluentes. À medida que a forragem fresca foi depositada nos silos, foi compactada com êmbolo de madeira, visando à produção de silagens com densidade entre $600 \mathrm{~kg} / \mathrm{m}^{3}$ a $800 \mathrm{~kg} / \mathrm{m}^{3}$. Os silos foram imediatamente fechados com tampas de PVC dotados de válvula tipo Bunsen, lacrados com fita adesiva e pesados. Posteriormente, foram armazenados à temperatura ambiente e a abertura foi feita aos 56 dias após a ensilagem. As silagens produzidas foram pesadas, homogeneizadas e présecas em estufa de ventilação forçada a $55^{\circ} \mathrm{C}$ até peso constante, em seguida o material foi moído em moinho de facas com peneira de malha de $1 \mathrm{~mm}$ para análises (Tabela 1).

Foram determinados os teores de matéria seca $(\mathrm{MS})$, proteína bruta $(\mathrm{PB})$, cinzas, fibra em detergente neutro (FDN), fibra em detergente ácido (FDA) e lignina. Com exceção das análises de FDN e FDA, feitas segundo Van Soest et al. (1991), as demais análises seguiram as recomendações de Silva \& Queiroz (2006).

Tabela 1. Composição química das silagens de diferentes frações da parte aérea (terço superior, sobras de plantio e planta inteira) de quatro variedades de Mandioca

\begin{tabular}{lccccccc}
\hline Variedade & Frações & MS & PB & Cinzas & FDN & FDA & Lignina \\
\hline \multirow{3}{*}{ Amarelinha } & TS & 25,68 & 16,30 & 6,32 & 59,3 & 41,63 & 14,51 \\
& SP & 26,04 & 17,46 & 6,16 & 64,36 & 43,48 & 14,85 \\
& PI & 26,73 & 14,15 & 5,19 & 67,13 & 42,38 & 15,19 \\
\multirow{5}{*}{ Sabará } & TS & 26,15 & 17,35 & 6,35 & 55,87 & 37,84 & 11,6 \\
& SP & 24,67 & 16,38 & 6,27 & 57,51 & 41,18 & 11,31 \\
\multirow{5}{*}{ Olho Roxo } & PI & 25,15 & 12,23 & 5,09 & 65,02 & 41,55 & 9,83 \\
& TS & 27,26 & 17,51 & 6,49 & 61,89 & 42,73 & 15,40 \\
\multirow{5}{*}{ Periquita } & SP & 27,17 & 17,18 & 6,25 & 61,11 & 42,80 & 16,25 \\
& PI & 26,86 & 13,74 & 5,15 & 64,05 & 42,59 & 13,84 \\
& TS & 20,93 & 20,05 & 6,52 & 56,83 & 38,89 & 13,36 \\
& SP & 22,69 & 20,54 & 6,24 & 58,79 & 43,91 & 15,46 \\
\hline
\end{tabular}

MS = matéria seca, $\mathrm{PB}=$ proteína bruta, FDN = fibra em detergente neutro, FDA, fibra em detergente ácido. $\mathrm{TS}=$ terço superior, $\mathrm{SP}=$ sobras de plantio, $\mathrm{PI}=$ planta inteira.

A estrutura do delineamento em blocos ao acaso mantida a campo, para controlar o efeito de fertilidade do solo, foi preservada para o ensaio de produção cumulativa de gases, com a finalidade de se obter as repetições do experimento.

A técnica in vitro semiautomática de produção de gases descrita foi conduzida de acordo com Maurício et al. (1999). A incubação foi feita em frascos de vidro com capacidade para $160 \mathrm{~mL}$ que previamente ao experimento foram lavados com água destilada e secos em estufa. Posteriormente foram injetados aos frascos dióxido de carbono $\left(\mathrm{CO}_{2}\right)$ e adicionados aproximadamente 1 grama das amostras a serem analisadas, pesando-se em balança digital, conforme os 
tratamentos propostos. Foram utilizados dois frascos por tratamento (réplicas) e frascos controle contendo apenas o meio de cultura e o inóculo. Para cada frasco, foram adicionados manualmente $90 \mathrm{~mL}$ de meio de cultura conforme Theodorou et al. (1994). Os frascos foram vedados com rolhas de borracha $(14 \mathrm{~mm})$ e para evitar que qualquer tipo de fermentação ocorresse, os frascos foram mantidos a $4^{\circ} \mathrm{C}$ durante a noite em geladeira comum. No dia seguinte, cinco horas antes da inoculação os frascos foram removidos da geladeira para estufa a $39^{\circ} \mathrm{C}$ até o momento da inoculação. Para coleta do líquido ruminal (inóculo), foram utilizados dois bovinos machos providos de cânula ruminal permanente. A coleta foi realizada manualmente no saco ventral do rúmen com auxílio de um pano $\mathrm{e}$ posteriormente houve a homogeneização dos inóculos provenientes dos dois animais, sendo então, acondicionados em garrafa térmica previamente aquecida $\left(39^{\circ} \mathrm{C}\right)$ e imediatamente levada ao laboratório. No laboratório, procedeu-se à filtragem do conteúdo em camada dupla de gaze com injeção contínua de $\mathrm{CO}_{2}$ e mantido em banho-maria, seguida imediatamente da inoculação.

A inoculação foi realizada através da injeção de $10 \mathrm{~mL}$ do inóculo por frasco através de seringa plástica graduada. Imediatamente após a inoculação, os frascos tiveram a pressão estabilizada através da inserção de agulhas $(25 \mathrm{~mm} x$ $7 \mathrm{~mm}$ ) nas tampas dos frascos. As agulhas foram posteriormente retiradas, os frascos manualmente agitados $\mathrm{e}$ colocados em estufa a $39^{\circ} \mathrm{C}$ e deu-se o início da contagem dos tempos de fermentação.

As leituras de pressão foram tomadas em maior frequiência durante o período inicial de fermentação e reduzidas posteriormente $(0 ; 4 ; 6 ; 8 ; 10 ; 12 ; 15$; $19 ; 24 ; 30 ; 36 ; 48 ; 72$ e $96 \mathrm{~h})$, sendo que após as leituras de $0 ; 12 ; 24 ; 48$ e 96 horas dois frascos eram removidos de cada tratamento para a determinação da degradabilidade.

A pressão dos gases foi obtida utilizandose o equipamento Datalogger Universal Logger AG100, um equipamento de bancada dotado de entrada analógica onde foi conectado o manípulo com uma agulha $(0,7 \mathrm{~mm})$ fixada em sua ponta para perfurar as rolhas de borrachas sintéticas encaixadas nos frascos. Este equipamento possui um botão de disparo na parte superior do manípulo para ser acionado para que o registro da pressão (psi) seja efetuado.

$\mathrm{O}$ volume foi medido por meio de uma seringa graduada $(20 \mathrm{~mL})$ nos tempos predeterminados $(0 ; 6 ; 12 ; 24 ; 48$ e 96 horas) também com uma agulha acoplada $(0,6 \mathrm{~mm})$. Imediatamente após a inoculação foi realizada a leitura inicial com o objetivo de padronizar a pressão e descartar o volume dos gases em todos os tubos. A partir da inserção da agulha inserida na rolha de borracha sintética, a pressão produzida no interior dos frascos foi verificada no leitor digital. Feita a leitura da pressão, a obtenção do volume de gases foi realizada puxando-se o êmbolo da seringa até que a pressão do transdutor de pressão retornasse ao valor zero.

Para quantificação da produção de gases provenientes do tampão e do líquido do rúmen, foram incubados dois frascos contendo apenas estes componentes. Para cada tempo de leitura, o volume de gás dos frascos com amostra foi subtraído do volume obtido nos frascos sem amostras. Ao serem obtidos os valores de pressão e de volume em cada tempo, estes foram somados aos valores das leituras anteriores, possibilitando assim a construção da curva correspondente à fração solúvel para cada tempo de incubação. 
O desaparecimento da matéria seca foi obtido pela relação entre a porcentagem do material inicialmente incubado e o resíduo após os períodos de $0 ; 12 ; 24$; 48 e 96 horas de fermentação. O resíduo da degradação foi obtido por meio da filtragem do conteúdo de cada frasco em cadinhos de porosidade 1 e posterior secagem em estufa a $100^{\circ} \mathrm{C}$ por 12 horas.

Os dados de produção cumulativa de gases oriundos da fermentação de cada tratamento foram utilizados no modelo de France et al. (1993):

$Y=A\{1-\exp [(-b(t-L)-c) x(\sqrt{ } t-$ $\sqrt{ } \mathbf{L})]\}$

Em que,

$Y=$ produção cumulativa de gases $(\mathrm{mL})$;

$A=$ potencial máximo de produção de gases;

$L=$ tempo de colonização (lag time);

$b$ e $c=$ taxas fracionais constantes;

Uma taxa fracional combinada à produção de gases $(\mu)$ foi calculada como:

$\mu=b+c / 2 \sqrt{ } t$

Em que,

$\mu=$ taxa de produção de gases;

$b$ e $c=$ taxas fracionais constantes;

$\mathrm{t}=$ tempo de incubação em horas.

Para ajustar os dados de degradabilidade às $0 ; 6 ; 12 ; 24 ; 48 \mathrm{e}$ 96h, foram utilizados os modelos matemáticos propostos por Mehrez \& Ørskov (1977) e Ørskov \& McDonald (1979), que possibilitaram estimar as degradabilidades potencial (DP) e efetiva (DE):

DP $=\mathrm{A}->\mathrm{t} \leq \mathrm{L}$

$\mathrm{DP}=\mathrm{a}+\mathrm{b}\left(1-\mathrm{e}^{-\mathrm{c} \times \mathrm{t}}\right) \rightarrow t>L$,

Em que:
DP $=$ degradabilidade do alimento $(\%)$ no tempo t (horas);

$\mathrm{A}=$ fração prontamente solúvel (\%);

$\mathrm{a}$ e $\mathrm{b}=$ parâmetros do modelo, cuja soma $(a+b)$ corresponde numericamente à degradabilidade potencial do alimento; e $\mathrm{c}=$ taxa de degradação (\%/hora).

Calculou-se também a fração solúvel potencialmente fermentescível do alimento (B):

$B=(a+b)-A$ ou $100-(A+C)$,

Em que:

$\mathrm{C}=$ fração indegradável (calculada como 100-DP).

A degradabilidade efetiva (DE) dos alimentos foi calculada da seguinte forma:

$\mathrm{DE}=(\mathbf{a}+\mathrm{b}) /[\mathrm{c} /(\mathbf{c}+k p)]$

Em que:

$\mathrm{kp}=$ taxa de passagem do alimento (\%/hora) pelo rúmen e foi considerada como 5\%/hora.

As estimativas dos parâmetros descritos no modelo matemático foram realizadas utilizando-se métodos interativos não lineares. Estes resultados ajustados, por estimativas de quadrados mínimos, foram obtidos a partir do uso do método Gauss - Newton, por meio do procedimento NLIN, com o auxilio do programa SAS (SAS Institute, 1999).

Para obtenção dos modelos estatísticos que medem a relação entre o volume de gases produzido durante a fermentação e a pressão (psi) utilizou-se o estudo de correlação por meio da linha de comando MANOVA do procedimento GLM de SAS. Uma vez detectada a correlação satisfatória (acima de $85 \%$ ) e significativa entre o volume e a pressão, utilizou-se a opção SELECTION=STEPWISE na linha de comando MODEL do procedimento 
GLM do SAS, para que a seleção do melhor modelo fosse feita automaticamente entre os modelos testados (linear, quadrático e cúbico), conforme mencionado pelo SAS Institute (1999).

Depois de obtidos os valores do volume acumulado de gases, taxa de degradação "c" e o tempo de colonização, os mesmos foram submetidos à análise de variância por meio do programa SISVAR (FERREIRA, 2000), além destes, os parâmetros de degradabilidade A; B; c; FI; DP e DE. E quando a análise de variância apresentou significância as médias de tratamentos (variedades e formas de aproveitamento) foram comparadas pelo teste de Scott-Knott ao nível de 5\% de probabilidade pelo SISVAR (FEREIRA, 2000).

\section{RESULTADOS E DISCUSSÃO}

Os dados de pressão variaram de 0 a 6,0 psi e os de volume entre 0 e $25,0 \mathrm{~mL}$ para as silagens da parte aérea de mandioca. Os tempos de leitura permitiram a obtenção de valores de pressão abaixo de 7,0 psi, de acordo com as recomendações de Theodorou et al. (1994). Segundo esses autores, valores de pressão acima de 7,0 psi causam instabilidade na correlação entre as variáveis e alterações no crescimento microbiano (Figura 1).

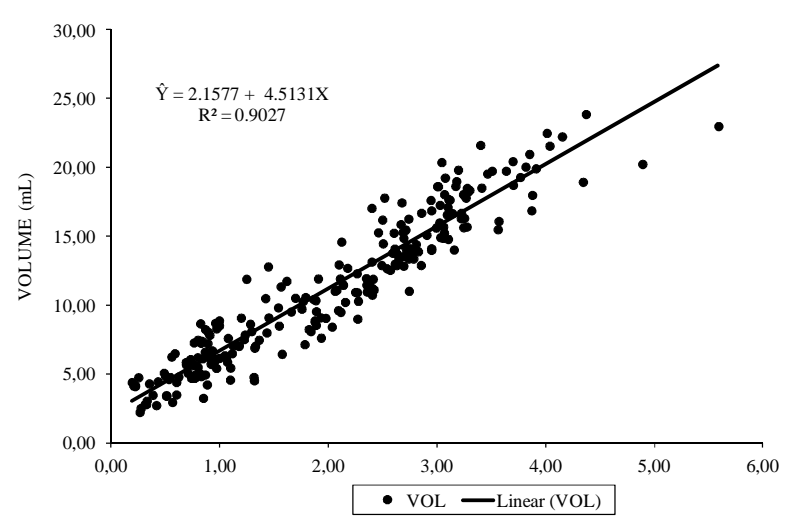

Figura 1. Dados de pressão e volume obtidos durante o ensaio de produção de gases usando como substrato as silagens de diferentes frações da parte aérea de quatro variedades de mandioca (psi=libra por polegada ao quadrado)

A equação de regressão predita para este experimento foi $\mathrm{V}_{(\mathrm{ml})}=2,157 \mathrm{X}+$ 4,13, $\left(\mathrm{R}^{2}=0,90\right)$, em que $\mathrm{V}=$ volume $(\mathrm{mL})$ e $\mathrm{P}=$ pressão (psi). A equação estimada neste trabalho apresentou um comportamento linear semelhante ao obtido por Araújo Neto et al. (2006) trabalhando com casca de coco, onde o volume predito de 4,96 $\mathrm{ml}$ para cada unidade de psi mostrou-se próximo e diferiu da equação obtida por Maurício et al. (1999), onde, $\mathrm{V}(\mathrm{ml})=-0,004+$ $4,43 \mathrm{P}+0,051 \mathrm{P} 2,(\mathrm{R} 2=0,99)$ ou em estudo realizado na Universidade de Reading-Inglaterra, onde também desenvolveram uma equação quadrática entre pressão e volume, a qual foi utilizada para estimar o volume obtido 
pela seringa na técnica manual de produção de gases (THEODOROU et al., 1994). De acordo com Maurício et al. (1999) esta modificação levou a uma redução no erro do operador, maior velocidade de leitura e aumento da capacidade do sistema. Evidenciando a importância da adaptação através de equações para a avaliação dos alimentos em diferentes altitudes.

$\mathrm{O}$ maior desaparecimento ruminal da MS ocorreu nos tempos entre zero e 24 horas, apresentando valores de degradação entre 5 e $20 \%$ no tempo zero de fermentação (Figura 2), provavelmente, devido à maior presença de compostos solúveis prontamente disponíveis. A partir de 24 horas de incubação observa-se que a degradabilidade da MS das silagens de todas as variedades e das diferentes frações da parte aérea manterem-se constantes. Assim como verificado por Silva et al. (2009) que no tempo zero de incubação as silagens apresentaram valores de degradação entre 20 e $35 \%$, paras silagens não emurchecidas, ocorrendo uma elevação linear dos valores à medida que se incrementaram a inclusão de raízes, demonstrando alto conteúdo de compostos solúveis prontamente disponíveis. A diferença na degradação final (96 horas) que variou entre 38,5 e $60,7 \%$ da MS nas silagens avaliadas neste trabalho pode ter sido influenciada pela proporção de parede celular apresentada nas forrageiras, sendo que na silagem do terço superior da variedade Amarelinha o teor de FDN foi de $59,30 \%$ e na silagem da planta inteira da variedade Periquita foi de $63,41 \%$ (Tabela 1).

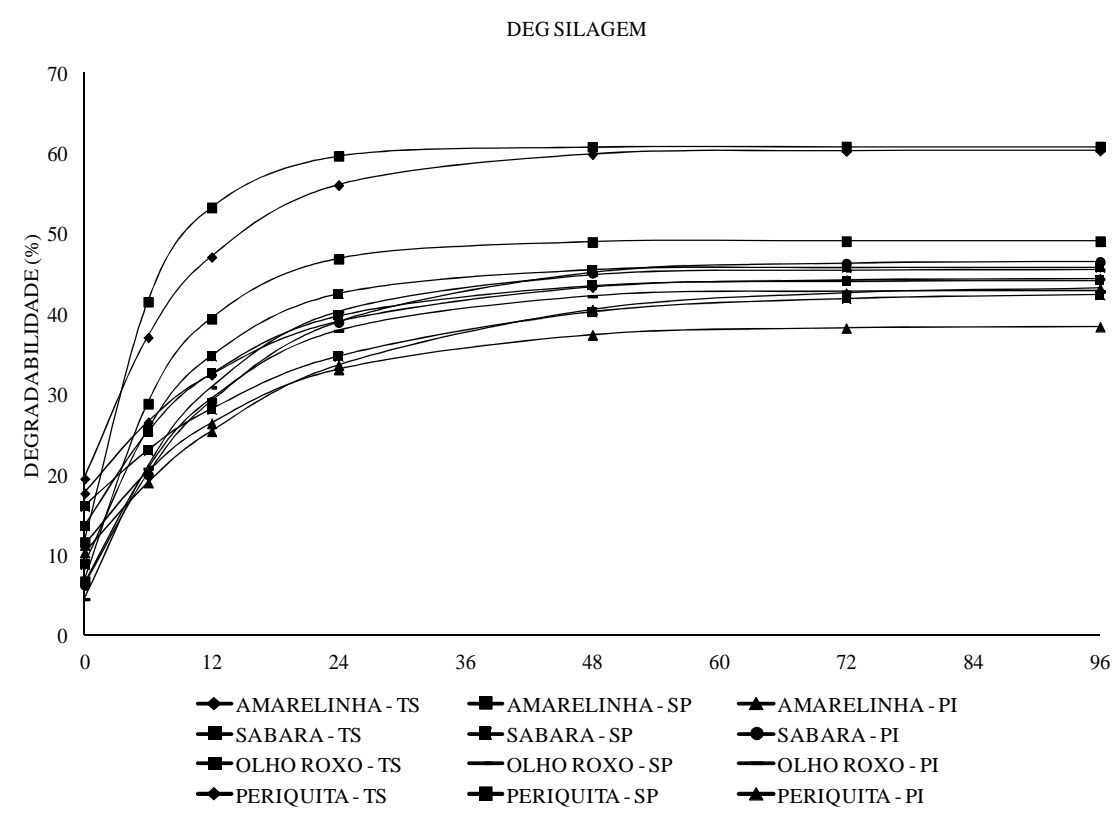

Figura 2. Degradabilidade de matéria seca das silagens de diferentes frações da parte aérea das quatro variedades de mandioca

Silva et al. (2009) mostraram uma taxa de degradação superior das silagens ao final das $96 \mathrm{~h}$, que variou entre 64,6 e
$88,4 \%$ da MS nas silagens de mandioca não emurchecidas e, 62,6 e 86,4\% para as silagens emurchecidas, respectivamente 
para os níveis 0 e $45 \%$ de inclusão de raízes, mostrando que a inclusão de raízes melhora as características de fermentação ruminal in vitro das silagens da parte aérea da mandioca, aumentando a disponibilidade de nutrientes digestíveis e de energia, o que consequentemente propicia maior degradação da matéria seca.

A silagem do terço superior da variedade Amarelinha apresenta maior degradabilidade no tempo inicial de fermentação. A partir de 6 horas esta fração foi inferior a fração sobras de plantio para a mesma variedade e superior as demais frações e variedades avaliadas (Figura 2). Constatou-se que a elevação do teor de FDN e FDA (Tabela 1) correlacionou-se negativamente com a taxa de degradação. As menores taxas de degradação foram para as variedades Amarelinha e Olho Roxo na fração planta inteira (Tabela 2). Kunkel et al. (2006) trabalhando com a correlação da FDN e FDA de leguminosas tropicais com parâmetros de cinética de fermentação ruminal mostraram que o aumento no teor de FDN e a elevação do teor de FDA das leguminosas tiveram correlação negativa com a taxa de degradação.

Observa-se na Figura 3, que as maiores taxas de produções de gases ocorreram no tempo inicial de fermentação, no período entre zero e doze horas, fato provavelmente ligado à fermentação dos carboidratos prontamente disponíveis. Destaque para a silagem da fração planta inteira da variedade Olho Roxo que apresentou a curva mais elevada.

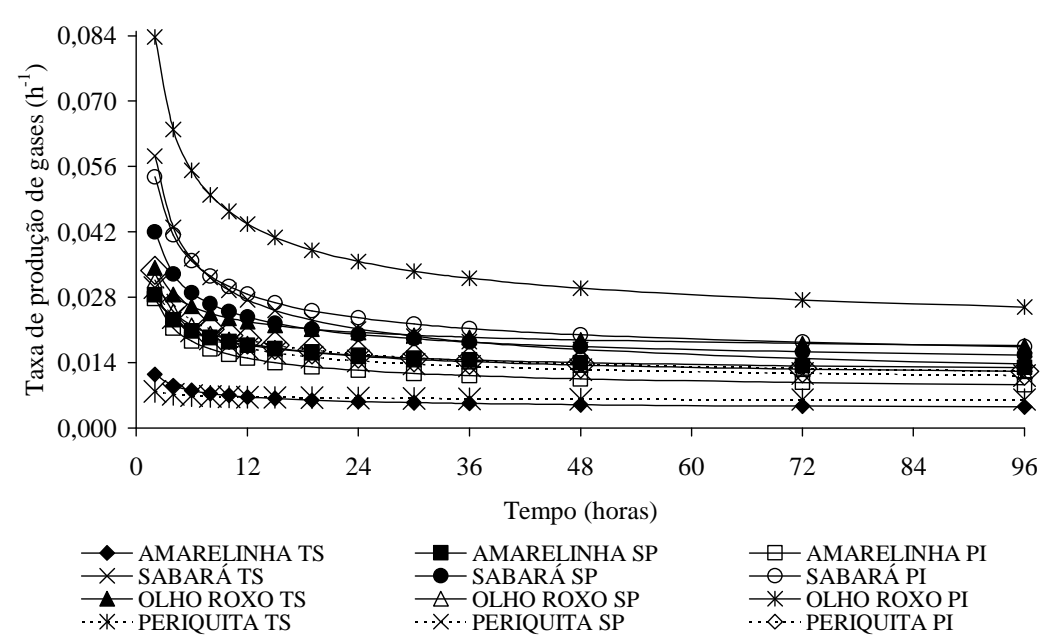

Figura 3. Taxa de produção de gases por tempo de fermentação (h) das silagens de diferentes frações de quatro variedades de mandioca

Para as produções cumulativas de gases entre os períodos de fermentação notase aumento com o decorrer dos processos de degradação até 48 horas, porém, as produções cumulativas de gases demonstraram estabilização após este tempo, indicando que até esta hora existiam compostos a serem fermentados, sendo o tempo máximo de incubação (96 horas) suficiente para que o máximo de degradação fosse atingido. As maiores produções de gases por hora foram obtidas aproximadamente às 48 horas de fermentação (Figura 4). 
Rev. Bras. Saúde Prod. Anim., Salvador, v.14, n.1, p.233-247 jan./mar., 2013 http://www.rbspa.ufba.br ISSN 15199940

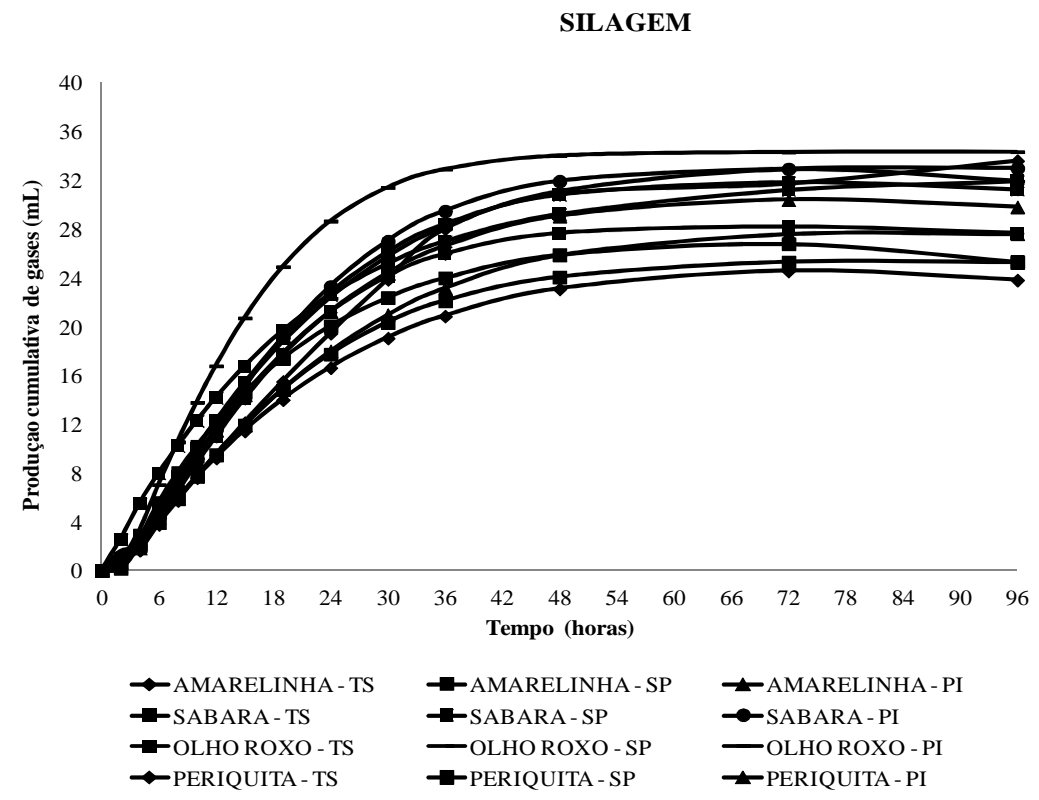

Figura 4. Produções cumulativas de gases (PCG) (em mL/g de MS) $x$ tempo de fermentação das silagens de diferentes frações de quatro variedades de mandioca

$\mathrm{Na}$ comparação entre as variedades e frações analisadas, destaque pode ser dado a silagem da variedade Olho Roxo na fração planta inteira que demonstra maior taxa de produção cumulativa de gases, o que pode estar relacionado ao menor teor de PB (Tabela 1). Santos et al. (2003) trabalhando com subprodutos proteicos concluíram que o caroço de algodão foi o alimento concentrado que apresentou menor produção de gases em todas as espécies estudadas, seguido dos farelos de algodão e soja, o que pode ser explicado pelo alto conteúdo de proteína desses alimentos. E de acordo com Khazaal et al. (1995), a incubação de substratos ricos em proteína resultaria na formação de bicarbonato de amônio, a partir de $\mathrm{CO}_{2}$ e amônia, reduzindo, assim, a contribuição de $\mathrm{CO}_{2}$ para a produção total de gases.

Resultados encontrados por Silva et al. (2009) mostraram que as silagens da parte aérea da mandioca emurchecidas ou não acrescidas de raízes apresentaram os menores valores de produção de gases
(144,0 e 125,8mL) em relação aos demais substratos contendo raízes, o que pode ser atribuído a menor proporção de carboidratos não fibrosos e elevado teor de PB.

Entretanto, as curvas de produção cumulativa de gases não refletem a mesma ordem demonstrada para a degradação do material, confirmando resultados descritos por Nogueira et al. (2006), que ao compararem substratos com diferentes teores de carboidratos solúveis, obtiveram maior degradação para os carboidratos com menor produção de gases e atribuíram essa menor produção de gases ao fato de que a fermentação de carboidratos solúveis proporciona maior produção de propionato e, consequentemente, menor produção de gases, pois a formação de propionato envolve a captura do hidrogênio $\left(\mathrm{H}_{2}\right)$ e não implica formação de dióxido de carbono $\left(\mathrm{CO}_{2}\right)$.

Não houve efeito $(\mathrm{P}>0,05)$ de variedade e fração da parte aérea quanto a fração insolúvel potencialmente degradável 
(B) da MS (Tabela 2), porém, houve efeito $(\mathrm{P}<0,05)$ para a fração solúvel (A) e taxa de degradação (c). Para a fração prontamente solúvel (A), houve destaque apenas na silagem da fração terço superior da variedade Periquita, podendo ser explicado por esta apresentar menores teores de FDN, FDA e lignina (Tabela 1). Em contrapartida, as silagens da fração planta inteira na variedade Amarelinha foi superior para a taxa de degradação (c).

Tabela 2. Fração solúvel (A), fração insolúvel potencial fermentável (B), taxa de degradação (c) da matéria seca das silagens de diferentes frações da parte aérea (terço superior, sobras do plantio e planta inteira) de quatro variedades de mandioca

\begin{tabular}{|c|c|c|c|c|c|c|c|c|c|}
\hline \multirow{3}{*}{ Variedades } & \multicolumn{3}{|c|}{ A } & \multicolumn{4}{|c|}{ B } & \multicolumn{2}{|c|}{$\mathrm{c}$} \\
\hline & \multicolumn{9}{|c|}{ Frações da parte Aérea } \\
\hline & $\mathrm{TS}$ & SP & PI & $\mathrm{TS}$ & SP & PI & TS & SP & PI \\
\hline Amarelinha & $15,52^{\mathrm{Aa}}$ & $9,30^{\mathrm{Aa}}$ & $11,30^{\mathrm{Aa}}$ & $40,18^{\mathrm{Aa}}$ & $47,36^{\mathrm{Aa}}$ & $27,06^{\mathrm{Aa}}$ & $0,06^{\mathrm{Aa}}$ & $0,09^{\mathrm{Aa}}$ & $0,14^{\mathrm{Ab}}$ \\
\hline Sabará & $13,88^{\mathrm{Aa}}$ & $10,63^{\mathrm{Aa}}$ & $6,03^{\mathrm{Aa}}$ & $28,72^{\mathrm{Aa}}$ & $34,0^{\mathrm{Aa}}$ & $40,53^{\mathrm{Aa}}$ & $0,06^{\mathrm{Aa}}$ & $0,10^{\mathrm{Aa}}$ & $0,07^{\mathrm{Aa}}$ \\
\hline Olho Roxo & $14,22^{\mathrm{Aa}}$ & $4,01^{\mathrm{Aa}}$ & $7,35^{\mathrm{Aa}}$ & $29,43^{\mathrm{Aa}}$ & $42,14^{\mathrm{Aa}}$ & $36,65^{\mathrm{Aa}}$ & $0,08^{\mathrm{Aa}}$ & $0,09^{\mathrm{Aa}}$ & $0,08^{\mathrm{Aa}}$ \\
\hline Periquita & $18,38^{\mathrm{Ab}}$ & $5,45^{\mathrm{Aa}}$ & $9,62^{\mathrm{Aa}}$ & $26,0^{\mathrm{Aa}}$ & $40,75^{\mathrm{Aa}}$ & $36,84^{\mathrm{Aa}}$ & $0,06^{\mathrm{Aa}}$ & $0,12^{\text {Aa }}$ & $0,06^{\mathrm{Aa}}$ \\
\hline $\mathrm{CV}(\%)$ & & 58,08 & & & 35,4 & & & 48,58 & \\
\hline
\end{tabular}

Letras maiúsculas idênticas significam semelhança estatística ( $p>0,05)$ em uma mesma coluna; letras minúsculas idênticas representam semelhança estatística em uma mesma linha, Pelo teste de Scott \& Knott ao nível de 5\% de significância.

$\mathrm{TS}=$ terço superior, $\mathrm{SP}=$ sobras de plantio, $\mathrm{PI}=$ planta inteira .

As degradabilidades efetivas (DE) calculadas (Tabela 2) mostram que as silagens das frações sobras do plantio e terço superior da variedade Amarelinha foram superiores a silagem da planta inteira, contabilizando $42,31 \%$ e $44,99 \%$, respectivamente, considerando taxa de passagem de $5 \% / \mathrm{h}$. Mesmo resultado foi encontrado para a degradabilidade potencial do alimento (DP) com $55,70 \%$ para a fração terço superior e $56,67 \%$ para a fração sobras de plantio (Tabela 3). A silagem da planta inteira da variedade Amarelinha apresentou maior fração indegradável (FI) $(61,64 \%)$, sendo que essa fração apresenta teores de $42,38 \%$ de FDA e $15,19 \%$ de lignina, responsável pela menor digestibilidade.

O potencial máximo de produção de gases (A) pode ser considerado como a expressão máxima da degradação ruminal de um alimento, sem considerar a limitação de tempo de permanência da digesta no rúmen. Os potenciais máximos de produção de gases variaram de $27,45 \mathrm{~mL} / \mathrm{g}$ de $\mathrm{MS}$ a $35,18 \mathrm{~mL} / \mathrm{g}$ de $\mathrm{MS}$, nas silagens avaliadas e não diferiram $(\mathrm{P}>0,05)$ para variedades e as frações da parte aérea (Tabela 4).

Os trabalhos de avaliação de silagens de mandioca pela técnica in vitro semiautomática de produção de gases são ainda escassos. A silagem de mandioca, quando comparada com outras forrageiras, como o girassol, com valor de A de $119 \mathrm{ml}$ com 100 dias de plantio, relatado por Pereira et al. (2005) apresentam produções de gases superiores ao da silagem de mandioca. Entretanto, estas comparações devem 
Rev. Bras. Saúde Prod. Anim., Salvador, v.14, n.1, p.233-247 jan./mar., 2013 http://www.rbspa.ufba.br ISSN 15199940

ser evitadas e restritas a grupos de alimentos de características próximas. Pois a relação propionato/acetato, resultante da fermentação de um alimento, pode interferir no volume de gases, podendo haver maior ou menor produção, dependendo das relações entre os ácidos graxos voláteis produzidos.

Tabela 3. Degradabilidade efetiva (DE), degradabilidade potencial (DP) e fração indegradável $(\mathrm{FI})$ da matéria seca das silagens de diferentes frações da parte aérea (terço superior, sobras do plantio e planta inteira) de quatro variedades de mandioca

\begin{tabular}{|c|c|c|c|c|c|c|c|c|c|}
\hline \multirow{3}{*}{ Variedades } & \multicolumn{2}{|c|}{$\mathrm{DE}$} & \multicolumn{5}{|c|}{ DP } & \multicolumn{2}{|c|}{ FI } \\
\hline & \multicolumn{9}{|c|}{ Frações da parte Aérea } \\
\hline & $\mathrm{TS}$ & SP & PI & $\mathrm{TS}$ & SP & PI & TS & SP & PI \\
\hline Amarelinha & $42,31^{\mathrm{Bb}}$ & $44,99^{\mathrm{Bb}}$ & $25,46^{\mathrm{Aa}}$ & $55,70^{\mathrm{Bb}}$ & $56,67^{\mathrm{Bb}}$ & $38,37^{\mathrm{Aa}}$ & $44,30^{\mathrm{Aa}}$ & $43,33^{\mathrm{Aa}}$ & $61,64^{\mathrm{Bb}}$ \\
\hline Sabará & $28,80^{\mathrm{Aa}}$ & $33,28^{\mathrm{Aa}}$ & $29,80^{\mathrm{Aa}}$ & $42,60^{\mathrm{Aa}}$ & $44,62^{\text {Aa }}$ & $46,57^{\mathrm{Aa}}$ & $57,40^{\mathrm{Aa}}$ & $55,38^{\mathrm{Aa}}$ & $53,44^{\mathrm{Aa}}$ \\
\hline Olho Roxo & $32,56^{\mathrm{Aa}}$ & $30,29^{\mathrm{Aa}}$ & $30,28^{\mathrm{Aa}}$ & $43,65^{\mathrm{Aa}}$ & $46,15^{\mathrm{Aa}}$ & $44,00^{\mathrm{Aa}}$ & $56,35^{\text {Aa }}$ & $53,86^{\mathrm{Aa}}$ & $56,00^{\mathrm{Aa}}$ \\
\hline Periquita & $32,95^{\mathrm{Aa}}$ & $34,05^{\mathrm{Aa}}$ & $29,07^{\mathrm{Aa}}$ & $44,36^{\mathrm{Aa}}$ & $46,20^{\mathrm{Aa}}$ & $46,47^{\mathrm{Aa}}$ & $55,64^{\mathrm{Aa}}$ & $53,80^{\mathrm{Aa}}$ & $53,54^{\mathrm{Aa}}$ \\
\hline $\mathrm{CV}(\%)$ & & 32,7 & & & 24,5 & & & 21,11 & \\
\hline
\end{tabular}

Letras maiúsculas idênticas significam semelhança estatística $(\mathrm{p}>0,05)$ em uma mesma coluna; letras minúsculas idênticas representam semelhança estatística em uma mesma linha.

$\mathrm{TS}=$ terço superior, $\mathrm{SP}=$ sobras de plantio, $\mathrm{PI}=$ planta inteira.

Tabela 4. Potencial máximo de produção de gases (A) em $\mathrm{mL} / \mathrm{g}$ de $\mathrm{MS}$, tempo de colonização (L) em horas e taxa de produção de gases $(\mu) \mathrm{em} \mathrm{mL} / \mathrm{g}$ de $\mathrm{MS} / \mathrm{h}$, em 96 horas de incubação das silagens de diferentes frações da parte aérea (terço superior, sobras do plantio e planta inteira) de quatro variedades de mandioca

\begin{tabular}{|c|c|c|c|c|c|c|c|c|c|}
\hline \multirow{3}{*}{ Variedades } & \multicolumn{2}{|c|}{$\mathrm{A}$} & \multicolumn{5}{|c|}{$\mathrm{L}$} & \multicolumn{2}{|c|}{$\mu$} \\
\hline & \multicolumn{9}{|c|}{ Frações da parte Aérea } \\
\hline & $\mathrm{TS}$ & SP & PI & $\mathrm{TS}$ & $\mathrm{SP}$ & PI & $\mathrm{TS}$ & $\mathrm{SP}$ & PI \\
\hline Amarelinha & $30,0^{\mathrm{Aa}}$ & $30,78^{\mathrm{Aa}}$ & $35,2^{\mathrm{Aa}}$ & $1,58^{\mathrm{Aa}}$ & $2,35^{\mathrm{Aa}}$ & $2,54^{\mathrm{Aa}}$ & $0,03^{\mathrm{Aa}}$ & $0,03^{\mathrm{Aa}}$ & $0,03^{\mathrm{Aa}}$ \\
\hline Sabará & $33,4^{\mathrm{Aa}}$ & $32,99^{\mathrm{Aa}}$ & $33,0^{\mathrm{Aa}}$ & $1,25^{\mathrm{Aa}}$ & $1,22^{\mathrm{Aa}}$ & $2,38^{\mathrm{Ab}}$ & $0,03^{\mathrm{Aa}}$ & $0,02^{\mathrm{Aa}}$ & $0,03^{\mathrm{Aa}}$ \\
\hline Olho Roxo & $31,0^{\mathrm{Aa}}$ & $30,7^{\mathrm{Aa}}$ & $34,3^{\mathrm{Aa}}$ & $1,67^{\mathrm{Aa}}$ & $1,93^{\mathrm{Aa}}$ & $2,38^{\mathrm{Aa}}$ & $0,02^{\mathrm{Aa}}$ & $0,03^{\mathrm{Aa}}$ & $0,04^{\mathrm{Bb}}$ \\
\hline Periquita & $28,9^{\mathrm{Aa}}$ & $30,3^{\mathrm{Aa}}$ & $27,45^{\mathrm{Aa}}$ & $1,69^{\mathrm{Aa}}$ & $2,14^{\mathrm{Aa}}$ & $2,35^{\mathrm{Aa}}$ & $0,03^{\mathrm{Aa}}$ & $0,04^{\mathrm{Bb}}$ & $0,02^{\mathrm{Aa}}$ \\
\hline $\mathrm{CV}(\%)$ & & 14,55 & & & 37,12 & & & 22,91 & \\
\hline
\end{tabular}

Letras maiúsculas idênticas significam semelhança estatística $(p>0,05)$ em uma mesma coluna; letras minúsculas idênticas representam semelhança estatística em uma mesma linha.

$\mathrm{TS}=$ terço superior, $\mathrm{SP}=$ sobras de plantio, $\mathrm{PI}=$ planta inteira .

A única diferença encontrada para o tempo de colonização foi para variedade Sabará, sendo que a silagem da planta inteira apresentou maior tempo de colonização em relação às demais frações, o que pode estar relacionado à 
maior proporção de parede celular da fração planta inteira nesta variedade de mandioca (Tabela 1). Ribas et al. (2007) descrevem que o tempo de colonização (L) representa o tempo compreendido entre a incubação até o início da ação microbiana sobre a amostra incubada. As reduções no tempo de colonização são favorecidas pela presença de substratos prontamente fermentáveis e por características físicas e químicas da parede celular da amostra.

As taxas de produção de gases $(\mu)$, um parâmetro que depende do tempo de incubação de cada alimento, variaram de 0,02 a $0,04 \mathrm{~mL} / \mathrm{h}$ para a MS. Na silagem da fração planta inteira, a variedade Olho Roxo apresentou maior taxa de produção de gases em relação às demais variedades. Já nas silagens das sobras do plantio a variedade Periquita superou as outras variedades com $0,04 \mathrm{~mL} / \mathrm{h}$ de taxa de produção de gases.

De acordo com Tomich (2003), partindo do princípio de que os gases produzidos refletem a degradação da amostra testada, a taxa e o potencial máximo de produção de gases são, provavelmente, os principais parâmetros para avaliar a qualidade de forrageiras testadas pela técnica de produção de gases. Sendo assim, a silagem da variedade Periquita na fração sobras de plantio e a Olho Roxo na fração planta inteira seriam consideradas de melhor qualidade, considerando sua taxa de produção de gases superior, mas em contrapartida, o seu potencial de produção de gases e o tempo de colonização não diferiram estatisticamente $(\mathrm{P}>0,05)$.

Além disso, de acordo com Pereira et al. (2005), forrageiras de boa qualidade apresentam altos valores de degradabilidade potencial e elevadas taxas de degradação. Partindo deste princípio, pode-se concluir que as silagens da variedade Amarelinha sob as frações da parte aérea terço superior e sobras de plantio provavelmente seria uma forragem de melhor qualidade para serem utilizada na alimentação dos ruminantes.

Quanto ao potencial de produção de gases, as silagens das diferentes variedades e frações da parte aérea de mandioca são similares. Em relação à degradabilidade ruminal, as silagens da variedade Amarelinha, nas frações da parte aérea terço superior e sobras de plantio, apresentam degradabilidades efetiva e potencial mais elevadas.

\section{AGRADECIMENTOS}

À FAPEMIG pelo auxílio financeiro e ao $C N P q$ e CAPES pelo auxílio com bolsas.

\section{REFERÊNCIAS}

ARAÚJO NETO, J.C.; VASCONCELOS, V.R.; PIMENTEL, J.C.M. Produção de gases durante a fermentação da casca do coco por meio da técnica in vitro semi-automática de produção de gases. In: REUNIAO

ANUAL DA SOCIEDADE

BRASILEIRA DE ZOOTECNIA, 43, 2006, João Pessoa. Anais... João Pessoa: Sociedade Brasileira de Zootecnia, 2006.

BARCELOS, A.F.; PAIVA, P.C.A.; PERÉZ,J.R.O.; TEIXEIRA, J.C.; CARDOSO, R.M. Avaliação da casca e da polpa desidratada de café (Coffea arabica L.) pela técnica de degradação in vitro de produção de gases. Revista

Brasileira de Zootecnia, v.30, n.6, p.1829-1836, 2001.

FERREIRA, D.F. Analises estatísticas por meio do Sisvar para Windows versão 4.0. In. REUNIÃO ANUAL DA 
Rev. Bras. Saúde Prod. Anim., Salvador, v.14, n.1, p.233-247 jan./mar., 2013 http://www.rbspa.ufba.br ISSN 15199940

REGIÃO BRASILEIRA DA SOCIEDADE INTERNACIONAL DE BIOMETRIA, 45., São Carlos. Anais... São Carlos, SP: UFSCar. p. 255-258.

FERREIRA, G.D.G.; OLIVEIRA, R.L.; CARDOSO, E.C.; MAGALHÃES, A.L.R.; BRITO, E.L. Valor nutritivo de co-produtos da mandioca. Revista Brasileira de Saúde e Produção Animal [online], v.8, n.4, p.364-374, 2007.

FIGUEIREDO, M.P.; SOUZA, L.F.; FERREIRA, J.Q. Cinética da degradação ruminal da matéria seca da haste, da raiz, do feno da parte aérea e da silagem de raiz de mandioca (Manihot esculenta Crantz) tratada com ureia. Brazilian Journal of Veterinary Research and Animal Science, v.43, n.1 p.11-17, 2006.

FRANCE, J.; DHANOS, M.S.; THEODOROU, M.K.; LISTER, S.J.; DAVIES, D.R.; ISAC, D. A model to interpret gas accumulation profiles associated with in vitro degradation of ruminant feeds. Journal of Theorical Biology, v.163, n.1, p.99-111, 1993.

GIRALDO, L.A.; GUTIÉRREZ, L.A.; SÁNCHEZ, J.; BOLÍVAR, P.A.

Relación entre presión y volumen para el montaje de La técnica in vitro de producción de gas em Colombia.

\section{Livestock Research for Rural}

Development, v.18, n.6, 2006.

Disponível em:

<http://www.cipav.org.co/1rrd/1rrd18/6 /gira18075.htm/>. Acesso em: 26 ago. 2010.

KHAZAAL, K.; DENTINHO, M.T.; RIBERRIO, J.M.; OERSKOV, E.R. Prediction of apparent digestibility and voluntary feed intake of hays fed to sheep: Comparison between using fiber component, in vitro digestibility or characteristics of gas production or nylon bag degradation. Animal

Science, v.61, p.527-538, 1995.

KUNKEL, L. J.; KOZLOSKI, G. V.; MEZZOMO, M. P.; ANDRESSA ANA MARTINS, A. A.; TIAGO ORLANDI. T.; ANA CAROLINA FLUCK, A. C. A correlação da FDN e FDA de leguminosas tropicais com parâmetros de cinética de fermentação ruminal. 2006. Disponível em: <http://portal.ufsm.br/jai/anais/eventos.ht m>. Acesso em: 26 abr. 2012.

MAURICIO, R.M.; MOULD, F.L.; DHANOA, M.S. A semi-automated in vitro gas production technique for ruminants feedstuff evaluation. Animal Feed Science Technology, v.79, p.321330, 1999.

MEHREZ, A.Z.; ØRSKOV, E.R. A study of the artificial fiber bag technique for determining the digestibility of feeds in the rumen. Journal of Agricultural Science, v.88, p.645-650, 1977.

MODESTO, E.C.; SANTOS, G.T.; VILELA, D.; SILVA, D.C.; FAUSTINO, J.O.; JOBIM, C.C.; DETMANN, E.; ZAMBOM, M.A.; MARQUES, J.A. Caracterização químicobromatológica da silagem do terço superior da rama de mandioca. Acta Scientiarum Animal Science, v.26, n.1, p.137-146, 2004.

MOTA, A.D.S.; ROCHA JÚNIOR, V.R.; SOUZA, A.S. de; REIS, S.T. dos; TOMICH, T.R.; CALDEIRA, L.A.; MENEZES, G.C. de C.; COSTA, M.D. Revista Brasileira de Zootecnia, v.40, p.1466-1473, 2011.

NOGUEIRA, U.T.; MAURÍCIO, R.M.; GONÇALVES, L.C. Comparação de substratos com diferentes quantidades de carboidratos solúveis utilizando a técnica in vitro semi-automática de produção de 
Rev. Bras. Saúde Prod. Anim., Salvador, v.14, n.1, p.233-247 jan./mar., 2013 http://www.rbspa.ufba.br ISSN 15199940

gases. Arquivo Brasileiro de Medicina

Veterinária e Zootecnia, v.58, n.4, p.633-641, 2006.

NUNES IRMÃO, J.; FIGUEIREDO, M.P.; PEREIRA, L.G.R.; FERREIRA, J.Q.; RECH, J.L.; OLIVEIRA, B.M. Composição química do feno da parte aérea da mandioca em diferentes idades de corte. Revista Brasileira de Saúde e Produção Animal [online], v.9, n.1, p.158-169, 2008.

ØRSKOV, E.R.; MCDONALD, I. The estimation of protein degradability in the rumen from incubation measurements weighted according to rate of passage. Journal of Agricultural Science, v.92, p.499-503, 1979.

PEREIRA, L.G.R.; MAURÍCIO, R.M.; GONÇALVES, L.C.; TOMICH, T.R.; RODRIGUES, J.A.S.; RODRIGUEZ, N.M. Avaliação das silagens de girassol (hibrido m734) obtidas em diferentes épocas de ensilagem pela técnica in vitro semi-automática de produção de gases. Brasilian Journal Veterinary Research Animal Science, v.42, n.4, p.276-283, 2005.

RIBAS, R.G.; MOYLE, C.Y.; MIYAKI, E.J.L. The assembly of montane biotas: linking Andean tectonics and climatic oscillations to independent regimes of diversification in Pionus parrots. Proceedings of the Royal Society B : Biological Sciences; v.274, n.1624, p.2399-2408, 2007.

SANTOS, R.A.; TEIXEIRA, J.C.; PEREZ, J.R.O.; PAIVA, P.C.; MUNIZ, J.A.; ARCURI, P.B. Estimativa da degradabilidade ruminal de alimentos utilizando a técnica de produção de gás em bovinos, ovinos e caprinos. Ciência e Agrotecnologia, v.27, n.3, p.689-695, 2003.
SAS Institute. Statistical analysis system: user's guide : statistics. Version 8.0. Cary, 1999.

SILVA, C.F.P.G.; FARIAS, D.H.; FIGUEIREDO, M.P.; BERNARDINO, F.S.; PEDREIRA, M.S. Avaliação de silagens da parte aérea e raízes de mandioca através da técnica in vitro semiautomática de produção de gases. In: ZOOTEC, 2009, Águas de Lindóia. Anais... Águas de Lindóia: FZEA/USP/ABZ, 2009.

SILVA, D.J.; QUEIROZ, A.C. Análise de alimentos: métodos químicos e biológicos. 3.ed. Viçosa, MG: Universidade Federal de Viçosa, 2002. $165 \mathrm{p}$.

SOUZA, A.S.de; ROCHA JÚNIOR, V.R.; MOTA, A.D.S.; PALMA, M.N.N.; FRANCO, M.O.; DUTRA, E.S.; SANTOS, C.C.R.dos; AGUIAR, A.C.R.; OLIVEIRA, C. R.; ROCHA, W.J.B. Valor nutricional de frações da parte aérea de quatro variedades de mandioca. Revista Brasileira de Saúde e Produção Animal [online], v.12, n.2, p.441-455, 2011.

SOUZA, A.S.de; ROCHA JÚNIOR, V.R.; MOTA, A.D.S.; ROCHA, W.J.B.; OLIVEIRA, C.R.; AGUIAR, A.C.R.de; SANTOS, C.C.R.dos; MENDES, G.A. Potencial forrageiro e valor nutricional do feno de diferentes frações da parte aérea de quatro variedades de mandioca. Revista Brasileira de Saúde e Produção Animal [online], v.13, n.3, p.604-618, 2012.

THEODOROU, M.K.; WILLIAMS, B.A.; DHANOA, M.S. A simple gas production method using apressure transducer to determine the fermentation kinetics of ruminant feeds. Animal Feed Science and Technology, v.48, p.185-197, 1994. 
Rev. Bras. Saúde Prod. Anim., Salvador, v.14, n.1, p.233-247 jan./mar., 2013 http://www.rbspa.ufba.br ISSN 15199940

TOMICH, T.R. Potencial forrageiro de híbridos de sorgo com capimsudão avaliados em regime de corte. 2003. 82p. Tese (Doutorado) - Escola de Veterinária, Universidade Federal de Minas Gerais, Belo Horizonte.

Van SOEST, P.J.; ROBERTSON, J.B.; LEWIS, B.A. Methods for dietary fiber, and nonstarch polysaccharides in relation to animal nutrition. Journal of Dairy Science, v.74, n.10, p.3583-3597, 1991.

Data de recebimento: 04/12/2012

Data de aprovação: 27/03/2013 